\title{
Implications of Accounting Information System Implementation in SMEs: A Study on Retail Business in Vlore Region
}

\author{
Dr. Ilirjan Lipi \\ Department of Business Administration, Economic Faculty, University of Vlora "Ismail Qemali" \\ Dr. Rudina Rama (Lipi) \\ Department of Finance, Economic Faculty, University of VIora "Ismail Qemali" \\ Dr. Xhiliola Agaraj (Shehu) \\ Department of Business Administration, Economic Faculty, University of Vlora "Ismail Qemali"
}

Doi:10.5901/mjss.2015.v6n3p553

\begin{abstract}
Due to the functions of AIS are realizing to the company, is evidenced that this system is playing a very important role in the management of operations and activity of the company, what makes AIS based more in computers and very necessary required from Albanian businesses including SMEs particularly in recent years. So, in this article is described exactly the implementation effort of AIS in SMEs that operates in business retail sector, also bringing in this way the testimony that despite of fact if SMEs have or not preliminary a manual accounting information system, they anyway display the need for accounting information ensured in standard or formal way. The main contribution of this study is that has generated facts and information that the implementation of AIS software in SMEs of retail sector in Albania is accompanied with many implications, which of course should be investigated also in other study contexts, before this proposal to be test in a quantity authentic study.
\end{abstract}

Keywords: information systems, AIS, software implementation, small and medium enterprise, retail business.

\section{Introduction}

Without big data analytics, companies are blind and deaf, wandering out onto the Web like deer on a freeway. Geoffrey Moor

According to European Commission report (2014) is emphasized that "SMEs ${ }^{1}$ are very important for the Albanian business economy, accounting for 81 \% (EU average: $67 \%$ ) of employment and generating about $70 \%$ (EU average: 58 $\%)$ of added value. Micro firms are particularly prevalent among SMEs dominate three sectors in terms of added value and employment: accommodation, wholesale and retail trade and construction" (pg 1).

Rapid developments of information technology have influenced for good also in the accounting firm itself, its processes and of course the quality of the information that it offers, which is the purpose of the accounting information systems, to guarantee in this way a qualitative information for its users and as a result likely for a good decision. Furthermore, besides the equipments that will support the accounting computerization of an enterprise, part of information technology will be software applications or productions which will help in data processing and in generation of reports and information, starting from operational reports that have processed the data of the transactions of the business up to accounting and management reports, saving all these inputs and outputs in a single location. However, a key factor in implementation of information technology is the conception of this process as a project, but is a missing culture in SMEs what can be due to obstacle all of this process.

However, we cannot fully consider AIS effectiveness and success if we are not aware that the information is a very important business resource beside other company resources. Thus, for example Hall (2011) explains that every day in the company should circulate a large amount of information as to internal or external users which are interested toward

1 Referring to SMEs classification in this study by Commission Recommendation 2003/361/EC of 6 May 2003, and by law No.8957, date 17.10.2002, "For small and medium enterprises". 
the company. Exactly in figure 1 is indicated the flow of this information as in bottom - up direction, so from the business operations referring here to main activities of production, sales, distributions etc. to three management levels according to the need that they have for the information.

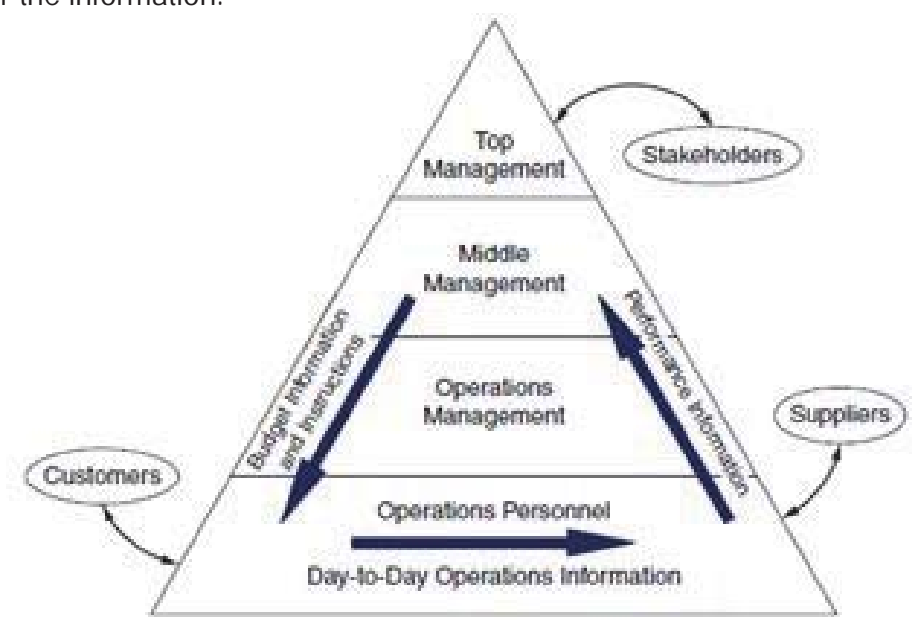

Figure 1: Internal and external flow of information. Source: From "Accounting Information System", by Hall, J.A., 2011, pg.4.

\section{Literature Review}

According to Lester and Tran (2008) an increasingly important factor for the survival and future of the company is undoubtedly the information technology. Information technology evidenced from word processing applications, those of networking, internet use, e-commerce, etc making in this way the information technology an important factor in the today world economy development. Dedrick, Gurbaxani, and Kraemer, (2003) have defined information of technology closely linked with using of computer and telecommunication equipments and their other elements such as hardware, software and other services. According to Rao, Metts, and Monge, (2003) companies' investments in information technology include activities such as payroll, human resources, accounting, supply chain management, and other functions. But despite these it seems like small enterprises are less orientated towards innovation of information technology compared to big companies which have the compulsory and as a result also with profitably investment in IT (Stimmel, 200; as cited in Lester \& Tran, 2008).

According to Lester \& Tran (2008) a problem of the small business in the IT investment remains the need for available resources (Pool, et al., 2006).

Moreover, information and planification complexity and system of control is one of the main factors for failure or success of the company mainly when the company grows and is more complex in the organization (Churchill \& Lewis, 1983). As a result growth of the company requires that these information systems to be implemented before the growth starts and the company owner manager to be also ready to decentralize the organization and to delegate responsibilities.

So, small business through information technology applications and automation of the processes and its operations to ensure collection and access of qualitative information will achieve to transform all the company (Dedrick, et al., 2003). However, according to Lester, et al. (2003) besides other variables a more decisive indicator of life cycle phase of the company would be complexity of procedures of information processing itself (as cited in Lester \& Tran, 2008).

According to Salehi, Rostami and Mogadam (2010) accounting means the functioning of the service that request to ensure to the information users quantitative information, but from another aspect AIS means an information system created to perform accounting process and functions. So, an AIS processes mainly financials data and transactions to ensure and offer to user's sufficient information to accomplish planification and control functions of the business. (Romney et al., 1997:2). An accounting information system can perform in a manual or automated way through the usage of information technology, however, despite this an AIS perform, collect, enter, process, store, and report data and information" (Salehi, Rostami and Mogadam, 2010, pg. 187). Based on the general definition of information system as a whole of the related components that are working together to collect, store and disseminate data for the purpose of planning, control, coordination, analysis and decision making, in this sense an AIS is the whole of the related components that are put together to collect information, raw data or ordinary data and transform them into financial data for the 
purpose of reporting them to decision makers (Salehi, Rostami and Mogadam, 2010, pg. 187). Regardless of these definitions the oldest system in business if we would refer to these information systems has been Management Information System. This system includes two different concepts such as "management" and "information" by highlighting unquestionable importance of information for management activities in business, so Management Information System includes many subsystems, where exactly in the whole Accounting Information System itself is one of these subsystems and even the earliest (Salehi, Rostami and Mogadam, 2010, pg. 187). Anyhow, effective establishment of such information system, so of an AIS is undoubtedly connected with more other specific organizative characteristics such as organizational culture, level of strategic planning and the information technologies (Salehi, Rostami \& Mogadam, 2010, pg. 187), so in this sense even the quality of financial information of the company itself will depend on the quality of configuration AIS itself, referring here on main functions of an AIS which are: "collecting and recording data about the activities and transactions; planning; processing the data and turning it into information to be used in decision-making for planning, application and control activities; and carrying out the necessary controls in order to protect the business assets" (Salehi, Rostami \& Mogadam, 2010, pg. 188).

Precisely because of these functions AIS have an important role for the management of the operations and activity of the company, which makes these applications based on computer more needed and required from Albanian businesses including SMEs especially recent years, despite this approach very prevalent in the world long time ago. And also if we will refer to the Albanian reality currently consciousness of the managers for the importance of this systems many organsations are placed in front of the need of implementation of an AIS even if obligated because of the need of control, adapted with clients and consumers or because of the competition for optimization of their processes, such as SMEs, larges business and public administration as well.

Although, implementation of an AIS can be a project with a high cost in the developed countries it looks like in Albania is not like this in relation with profits that come to the business from this system, but absence of the conscious for all the factors that influence in the success of this implementation in Albanian companies is making it harder this adaptation despite the need of the companies for an AIS. According to Salehi, Rostami and Mogadam (2010) the studies also testify for other implications in relation with implementation of AIS for example Flynn (1992) has testify that only 20\% of information systems are used in effective way, while for other part this application can bring a negative effect, testifying for the importance that has the effective implementation of an information system. Exactly Flynn (1992) explains that the effectiveness of AIS can be received providing management information to assist concerned decisions with regard to the successfully managing of corporations" (Salehi, Rostami \& Mogadam, 2010, pg. 188). So, according to Corner (1989) the effectiveness of AIS "can be evaluated as added value of benefits", while Gelinas (1990) defines the effectiveness of AIS "as a measure of success to meet the established goals" (Salehi, Rostami \& Mogadam, 2010, pg. 188). As a conclusion researchers have estimated fulfillment of mission of an AIS through the successful usage of it referring here fulfillment and completion of needs of its users mainly internal but also external. However, if we would refer studies in this field it seems that there are different methods of effectiveness of AIS in business (Salehi, Rostami \& Mogadam, 2010)

\section{Methodology of Study}

The plan of accounting software implementation is a very important project because otherwise the company would invest in late period's time, energy and additional money. Impact of information systems (or ERP) on financial performance of companies requires time and studies evidence a period of several years (Poston \& Grabski 2001), so a good planification of the implementation of the process of accounting software to avoid unexpected expenses and to avoid miss communication through administration of business is needed.

The plan of implementation of accounting software should be first step of the process and in this phase are specified the steps that should follow for the effective implementation of accounting software.

Specification and clarification of the information which should pass from the old system even from the manual in the new one is very important to realize wit success implementation of AIS in function of business necessities even the companies do not show careful in this phase this will be accompanied with additional cost.

But also the planning of assets is another very important moment of the implementation plan, so is necessary that the business to plan which actual computer equipments and what is needed further and to identify capabilities of their human resources. 


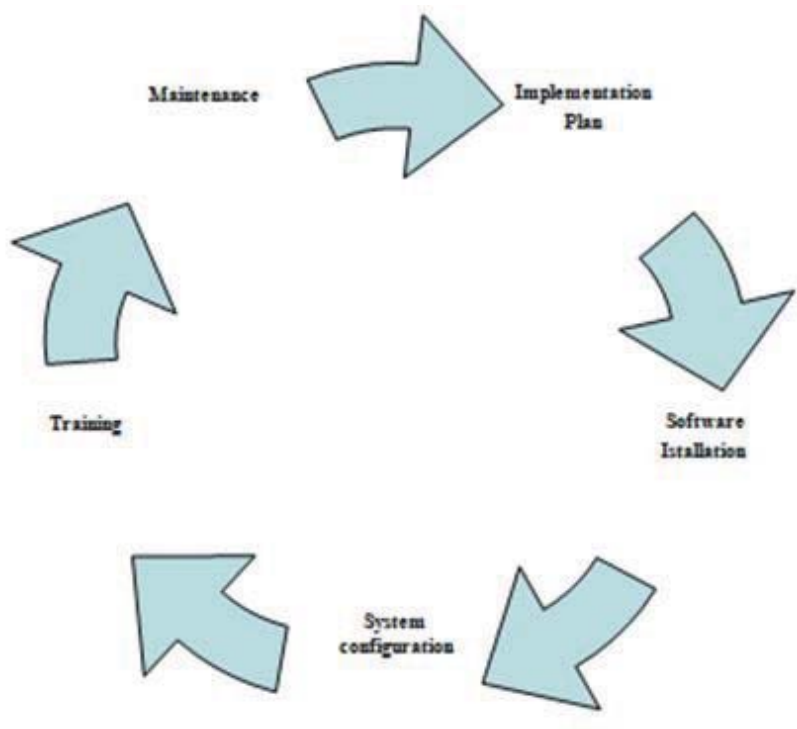

Figure 2: Conceptual cycle of accounting software implementation

The article aims to evidence implications during AIS implementation in retail business in Vlore region. To enable generation of the facts and to conclude in study proposal, this study through a qualitative approach has explored empirical data of 20 interviews directed to 20 owner- manager in 20 retail businesses in Vlore region. On study focus have been companies of retail sector with high sale level, long life and commercial activity over 5 years, which occupy an important weight regarding the market and their commercial activity in the companies of this sector in Vlore region.

The research problem of this study with focus on AIS implementation is that:

Retail business in Vlore region do not plan with careful the implementation of AIS process bur request to solve only emergency problems and this is accompanied with additional costs in medium and long terms and influence in its quality and effectiveness of this system. Usage with effectiveness of AIS asks also great abilities and qualified personnel of the business.

\section{Findings and Discussions}

Study's results for the implementation of accounting software in retail business Vlore region are clearly presented by pointing the necessity for improvement in steps and activities of implementation.

The first step in the implementation cycle is the implementation plan of AIS. Precisely in relation to this phase, owner - managers of the businesses included in the study are interviewed regarding: "Which were the reasons that you decided to implement an AIS"?

According to the data showed out the fact that according to them the main reasons for the planning of implementation of automated AIS were measuring and control of inventory, invoicing and registration of daily sales and automated configuration of sales prices. Long list of sales prices is testified that is one that is one of the main reasons for implementation of AIS, which appeared as a worry even for sales personnel especially in cases when purchasing and selling price of the articles vary significantly from period to period. So, memorizing of long lists of selling prices was presented as a problem from all owner-managers of the companies included in the study, influenced this also from the sector itself where they operate being that they show a big number of products.

Identification and inventory measurement situation in real time is another worrying problem for businesses. These commercial activities posses large warehouse and in many cases are problem control and measurement of inventory situation in real time. Between 20 retail businesses around 18 of them raise as a very important problem the issue of stocktaking in real time of warehouse and time when should order for supply and purchasing conditions.

Registration and measurement of daily sales of commercial businesses and reconciliation with cash is ranked as third reason that businesses are encouraged in their decision for implementation of accounting software. Until the moment of implementation of software operated with the principle of cash accounting where frequently cash receipts were equivalent to daily sales, but the problem hampered for sales with delayed payments and in relation with accounts 
receivables, so in 20 retail businesses in around in 16 of them this problem is ranked as another reason for decision of implementation of accounting software.

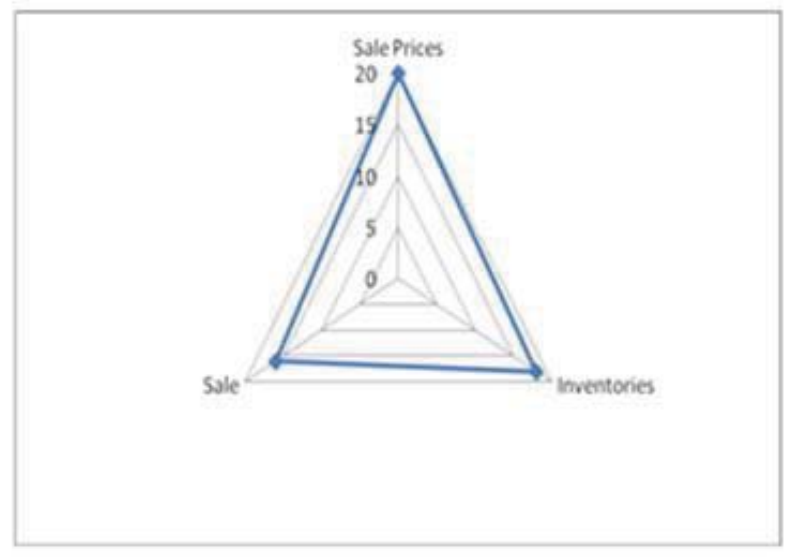

Figure 3: The main reasons of AIS implementation by Retail Business Sector in Vlora Region Source: Study research data.

Second result generated from the study is related to the usage of AIS implementation plan by retail business firms, exactly second question directed to retail business was "Have you done an implementation plan of AIS before the start of its implementation process?"

Table 1: Planning the implementation plan of AIS by Retail Business Sector in Vlora Region.

Source: Study research data

\begin{tabular}{|c|c|c|}
\hline & Yes & No \\
\hline AlS implementation plan before the start of the process & 6 & 14 \\
\hline
\end{tabular}

A considerable part of commercial companies do not have an implementation plan for AIS. Only $30 \%$ have an implementation plan, while $70 \%$ of them do not draft and concept such a plan, despite the importance it has for the success of AIS itself.

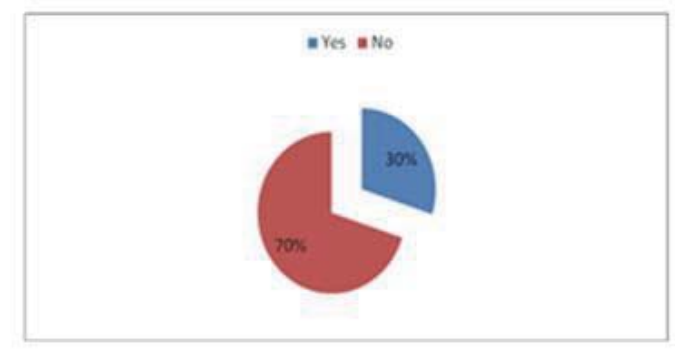

Figure 4: Planning the implementation plan of AIS by Retail Business Sector in Vlora Region.

Source: Study research data

Absence of draft and preliminary conception of an implementation plan from these businesses is very worrying, because being that short and medium terms of retail businesses are faced with other expenses and it creates distrust climate between retail businesses and software vendors. At the same time is added inefficient time of work spent from software vendors. Lack of an implementation plan of AIS is estimated and proves the lack of businesses' objectives or at least estimation with seriousity of businesses objectives from retail firms.

In connection with a very another important aspect of implementation of AIS, regarding the investment budget in accounting software, results that $90 \%$ of firms have forecast and plan in the beginning only monetary cost of the software, 
and later they were obligated to change hardware, which brought excess of financial value also paying additional services or yearly maintenance contracts stimulated from the necessities of changing hardware after the software installation. Delayed purchasing of new hardware brought for software vendors additional working hours, while for business itself brought the need of returning of the working processes behind old techniques of manual operations because of the required time which requested replacement of and transferring of AIS data in new hardware.

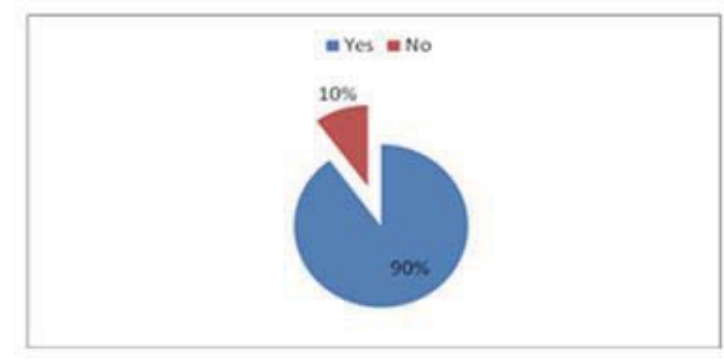

Figure 5: Planning the cost of AIS software by Retail Business in Vlora Region

Source: Study research data

Organisative structure of retail business is another important characteristic investigated during the study, precisely the question that investigates around this characteristic of the firm is "if installation of AIS is accompanied with a changing of actual working processes and duties in firm."

Despite their organization level of the firm, studied businesses had already a functional organisative structure, but in the moment of implementation of AIS was necessary a reconfiguration of organisative structure in $80 \%$ of the cases.

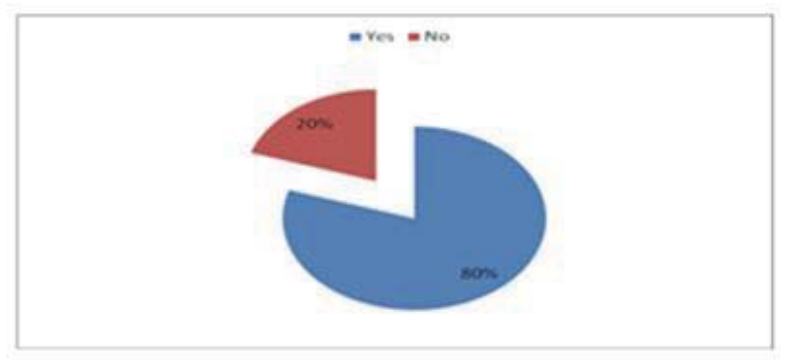

Figure 6: Reorganization of the organizational structure by Retail Business in Vlora Region Source: Study research data

And precisely in 8 of these businesses experienced reconfiguration of staff, so in $50 \%$ of them came out the need for increasing the number of personnel and moreover the qualified one with good abilities on AIS, being that they will use an accounting software to do their work. While in 12 retail businesses (where in 8 of them were done structure and personnel reorganization and 4 other where there was not reorganization) was necessary the training of all personnel that already would perform tasks and a part of firm's operation through innovator system supported in usage of technology.

However, the process of reconfiguration was done as necessity during implementation of AIS and was not planned before, even not considerate as a process continued from owner-managers but only as a moment orientation, despite that organization of the business and furthermore organisative structure should be constantly in adaption with activity and transaction of the firm, ways which developed with implementation of AIS itself.

Table 2: Reorganization of the organizational structure by Retail Business in Vlora Region

\begin{tabular}{|l|c|c|}
\hline & Yes & No \\
\hline Reconfiguration of the processes of work and tasks from the beginning & 16 & 4 \\
\hline Continued improvement and fit of organizational structure & 1 & 19 \\
\hline
\end{tabular}

Source: Study research data 
Regarding also the reorganization from the study results that only $5 \%$ of the business continued analyze of working process and in later periods so after implementation of AIS, aiming constantly improvement and adaption of processes and works in function of firm's objectives.

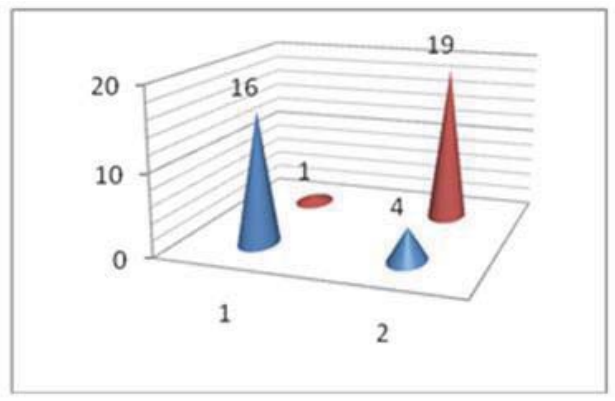

Figure 7: Redesign of processes in continuation by Retail Business in Vlora Region Source: Study research data

A very important part of implementation plan is analyzing of hardware that retail businesses use.

Question directed to owner-managers of this business regarding this very important aspect for all processes and activities that firm does is "if the firms use existing hardware or purchase new hardware for implementation AIS software", which seems that presents interesting results.

Around $90 \%$ of retail businesses look like do not invest in new hardware for installation and implementation of AIS using exactly the existing one.

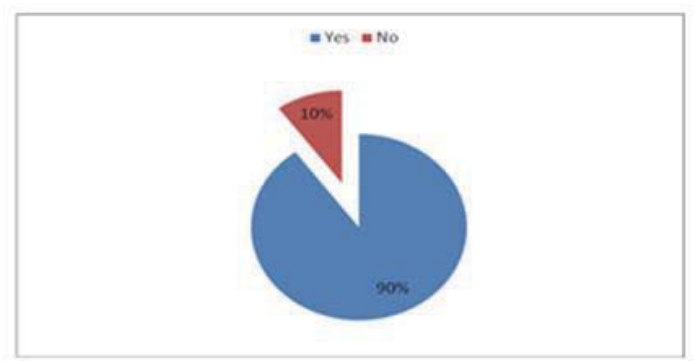

Figure 8: Use of existing hardware for AIS implementation by Retail Business in Vlora Region Source: Study research data

Hardware of these businesses was preliminary tested from software vendors and around $50 \%$ of them had resulted not appropriate for installation and implementation of AIS. However, regardless tenacity of owner-managers for usage of existing hardware which would affect the effectively of AIS, software vendors accepted installation and implementation of AIS in old hardware for not prevented the sales process of software.

From the data of the interviews was witnessed that in the beginning productivity of AIS was rated satisfactory, but later it looked like the speed of software work on answer time to perform selling transaction and accounts receivables because of amortization of hardware was low.

So, around $44.5 \%$ of firms which used existing hardware for implementation of AIS because of low speed were obligated to substitute existing hardware within a year.

Table 3: Use of existing hardware for AIS implementation by Retail Business in Vlora Region

\begin{tabular}{|c|c|c|}
\hline & Yes & No \\
\hline Firms use existing hardware & 18 & 2 \\
\hline
\end{tabular}

Source: Study research data 
The second step is AIS installation. This is a process that is realized both by the local retail store of software vendor as well as by the software company itself. Problems of installation of AIS software in this study are important as a step or phase of implementation process of AIS. Both the local software retail store and the software company analyze in continuation their processes, tasks and activities of AIS implementation to reduce unnecessary processes and working hours or days.

So an issue raised in the study is related to preliminary test of AIS and from the data collected results that around $70 \%$ of retail businesses have preliminary tested application of AIS, and also this process is requested from them.

Table 4: Testing of AIS by Retail Business in Vlora Region

\begin{tabular}{|c|c|c|}
\hline & Yes & No \\
\hline Testing AIS & 14 & 6 \\
\hline
\end{tabular}

Source: Study research data

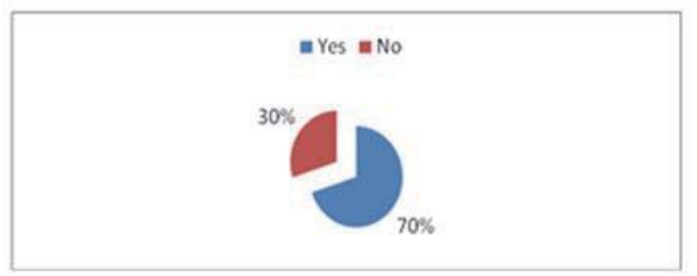

Figure 9: Testing of AIS by Retail Business in Vlora Region

Source: Study research data

Testing of AIS in reality means a request from retail business itself to see and preliminary estimate functioning and application of AIS software across their transaction and accounting processing. In many cases the process of testing is evaluated as a security and guarantee that retail businesses requiring estimating before taking decision of buying AIS software.

Third step of AIS implementation in retail business is software configuration. The question that is raised regarding this subject is "Who has done implementation of the software, firm's staff or software vendors", has testify that all studied businesses or $100 \%$ of them have followed the same way as it is describe as following.

Configuration process of AIS in this firms is configurated in two phases, where in first phase is done configuration of AIS as per firms request itself and this process is realized by the local retail software vendor.

Table 5: Configuration of AIS by Retail Business in Vlora Region

\begin{tabular}{|c|c|c|}
\hline & Yes & No \\
\hline Configuration of AIS & 16 & 4 \\
\hline
\end{tabular}

Source: Study research data

The other important phase of configuration has been identification and collection of preliminary data of firm transactions which after are registered in AIS files. This operation is realized from the staff of the firm itself during the process of implementation of the software.

In this phase in the same time is dedicated importance also to preliminary information organizing, cleaning from details and unnecessary qualities and careful transferring of it in AIS files.

The fourth step of AIS implementation in retail business is staff training. Regarding staff or personnel of the firm that would use and would interact with AIS, from firm side is made possible that training of the personnel to be done before starting of the process of implementation of AIS. In the training were included existing staff and the new one which added during configuration of organisative structure of these firms. Although some of staff members preliminary knew other accounting software, anyway they were optimists in the choice made because of the reason of advantage of this AIS software and above all because of the support that offered software vendor. 
The fifth step for implementation of AIS in retail business is software maintenance. Regarding this subject look like has not missed support of local software vendors gave to these businesses concerning with software maintenance. To explore this subject the question directed to owner-managers consist on "How sufficient has been support of local software vendors given for the maintenance of software?" measuring this scale with a Licert item from 1-5 (from lower to higher) the result of which are summarized in table7.

Table 6: Support and maintenance by local software vendor, Retail Business in Vlora Region

\begin{tabular}{|c|c|c|c|c|c|}
\hline & 1 & 2 & 3 & 4 & 5 \\
\hline Support and maintenance by local software vendor & 2 & 2 & 2 & 12 & 2 \\
\hline
\end{tabular}

Source: Study research data

Around $10 \%$ of businesses estimate on the average very good, $60 \%$ of the businesses evaluate very good and $10 \%$ estimate excellent support of local selling point. In this way only $10 \%$ estimate poorly and $10 \%$ weak. The result of $20 \%$ with evaluation under average is enough disscutable because a part of current staff in the beginning of implementation do not have capability and competence to use AIS.

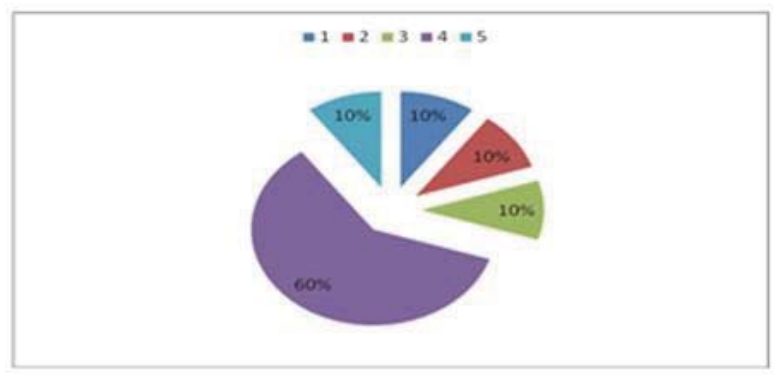

Figure 10: Support of sale local point, Retail Business in Vlora Region

Source: Study research data

Software maintenance provided to these retail businesses as consisted in the form of maintenance service with request of client2 or guaranteed through maintenance contracts. Regarding software maintenance and support contract it is an agreement between AIS software vendor and customer with the maximum term of duration by one year, but the maintenance agreement is signed in the end of three months of software guarantee period. One-year Service Agreement gives firms a priority in caring of problem solving that come as a result of various defects during software use. However despite the fact that the annual agreement is associated with an annual cost, it should be simply considered as a necessary fee required obtaining the guarantee of fast and qualitative software maintenance service.

\section{Conclusions}

It appears that rapid development of technology have significantly influenced and firms of developed countries what appears in their trend for evaluation of working processes in enterprises of all sizes without excluded also SMES, changing mainly the processing transaction process and also influencing in the processes of information accounting system of the enterprise.

Because of a very important role that AIS has for the management of operation and activity of the firm, did these applications very important for Albanian SMEs especially recent years, despite these information systems are spread over the world long time ago.

However implementation of AIS results to be a high cost project for developed countries look like Albania such implementation is not expensive in proportion with business profits generated from application wit effectiveness of this information system, but the lack of consciousness from Albanian SMEs and particularly of owner-managers for all factors that influence in the success of this implementation is making harder this process and maybe more expensive and less effective.

What is clear from study results about implementation in retail business is the fact that through implementation of 
AIS software businesses intend to solve only specific problems which are accumulated and are made obstacle for the normal flow of their operations, so owner-managers in the moment that decide to implement an AIS for their transaction cycle do not analyze a full plan to precede the effective implementation of accounting software. In these problems that businesses hurry up to solve through accounting software which more important are stock review, sale prices, or daily, weekly and monthly estimation of sales.

However, what I suggest and prove based on the experience and findings of this study is importance that has the large study of implications and other factors that influence in implementing of accounting software in SMEs of retail sector in Albania, for the fact itself that identification end evidence of tem forecast not only problems in effectiveness of AIS, but testify further other complexities in firm organizing which also witnesses also for phase or life cycle of firm itself.

Also, in many cases seem like the firms have acute shortage of knowledge for necessary hardware for implementation of AIS. Businesses hesitate in investment for hardware and the money spent for hardware are evaluated as excess cost, also accounting and financial wisdom and knowledge between owner-managers in retail business significantly vary.

Lack of vision for planning hardware brings problems in working speed of AIS and increase spent time for processing of many transactions mainly sale process, causing dissatisfaction to the clients and firms itself. At the same time in short-term periods firms obligated to invest again in hardware equipments.

The plan for AIS implementation is skipped by the firm plans and so this process is planned from local software vendor itself before the project starts, so businesses should concept as an advantage that the vendor offers, even though they still hesitate in following and execution of an implementation plan. Culture of these firms is a key factor that influence in negative translation of implementation plan with the initiative of the vendor, representing it as seller initiative to realize a bigger value of selling from this project.

Another hypothesis which should be considered in future studies is related to the attitude that AIS vendors hold regarding the standards of their clients' hardware before AIS implementation.

Precisely regarding this subject is recommended that marketing and sales personnel of software companies should spend more time with their clients to inform and to make them more conscious regarding the importance and standards of hardware where should be implemented AIS software, should be orientated stronger and develop more marketing functions and not to focus only to final selling process.

Forecast of monetary values for the implementation plan process of accounting software is another problem of retail business which also shows for problems in financial management practices regarding the planification in the business.

At the same time implementation of AIS influence also in the reorganization of many working processes in businesses, even though look like few businesses continue to analyze working processes even on AIS postimplementation period.

Existence of a local retail and service store is very important for effective implementation of AIS from businesses, because after the business culture this is evaluated as guarantee for readiness of maintenance service and later support.

Also, other hypothesis and proposals for future studies should be raised about:

- Influence of AIS in organizing of processes, activities, operations and works of the firm.

- Trend of the firm for not changing.

- Division of the functions of AIS implementation project between software companies and local software vendors

- The significance of the spread of local software vendors for AIS Implementation in SMEs in Different regions

- With separating of the duties, responsibilities, authority and information circulation in businesses.

- Centralized decision and style of owner-managers decision of SMEs what looks as a problem that appears in this study regarding the main role of owner-managers in taking decision for implementation of AIS in firm?

This research is organized through a qualitative research approach, and as such has its limitations as following:

- The study is orientated only in one sector and precisely in retail business and as not reflected and explored other sectors of business which have also implemented AIS software for practice and activity of their businesses.

- Also the regional character raises another limit of the study including only firms that operate in Vlore region. .

- Questionnaire is distributed in a limited number of retail businesses because of its qualitative approach, although firms included in the study are healthy representatives of this sector from selling volume and function duration point of view of them in the market.

However, this study is also important because of: 
- Highlight the reality of using AIS in specific regions and open the road to extensive studies.

- Hack through discussions on the importance, implications and value of the implementation of AIS in business.

- Awareness business administrators for the importance of AIS implementation plan.

- Push out other studies about the implementation and impact of AIS in small and medium enterprises, especially in developing countries, and moreover in Albania where the studies around this field are in their genesis and are IT perspective and not from accountant's perspective.

\section{References}

European Commission Report. (2014). Enterprise and Industry 2014 SBA Fact Sheet Albania.

Information Technology Capabilities: Suggestions for SME Growth Donald L. Lester, Middle Tennessee State University; Thuhang T. Tran, Middle Tennessee State University

Commission Recommendation 2003/361/EC of 6 May 2003, concerning the definition of micro, small and medium size enterprises", in OJ L 124/36, 20/05/2003.

Ligji nr.8957, datë 17.10.2002, "Për ndërmarrjet e vogla e të mesme".

Salehi, M., Rostami, V., \& Mogadam, A. (2010). Usefulness of Accounting Information System in Emerging Economy: Empirical Evidence of Iran. International Journal of Economics and Finance 2(2):186-195.

Poston, R. \& Grabski, S. (2001). Financial Impacts of Enterprise Resource Planning Implementations. International Journal of Accounting Information Systems, 2(4), 271-294.

Hall J.A, (2011). Accounting Information System. 7th ed, South-Western Publishing Co. pg. 4.

http://www.erpsoftwareblog.com/2009/11/5-steps-to-a-successful-implemention-of-your-new-accounting-system/ | ERP Software Blog https://www.sysaid.com/blog/entry/15-it-trends-for-2015?utm_source=facebook\&utm_medium=cpc\&utm_campaign=blog-15-it-trends-for2015

http://smallbusiness.chron.com/effective-project-management-small-business-organization-41274.html 